\title{
Defective Fluid Transport by Cystic Fibrosis Airway Epithelia
}

\author{
Jeffrey J. Smith, Philip H. Karp, * and Michael J. Welsh* \\ Department of Pediatrics and *Howard Hughes Medical Institute, Departments of Internal Medicine, and Physiology and Biophysics, \\ University of Iowa College of Medicine, Iowa City, Iowa 52242
}

\section{Abstract}

Cystic fibrosis (CF) airway epithelia exhibit defective transepithelial electrolyte transport: cAMP-stimulated $\mathrm{Cl}^{-}$secretion is abolished because of the loss of apical membrane cystic fibrosis transmembrane conductance regulator (CFTR) $\mathrm{Cl}^{-}$ channels, and amiloride-sensitive $\mathrm{Na}^{+}$absorption is increased two- to threefold because of increased amiloride-sensitive apical $\mathrm{Na}^{+}$permeability. These abnormalities are thought to alter respiratory tract fluid, thereby contributing to airway disease, the major source of mortality in this genetic disease. However, the underlying hypothesis, that fluid transport is abnormal in CF airway epithelia, has not been tested. Most conjecture about fluid transport is based on measurements of $\mathrm{Na}^{+}$and $\mathrm{Cl}^{-}$ transport performed under short circuit conditions in Ussing chambers. But such studies differ from in vivo conditions in that transepithelial voltage and mucosal fluid composition are held constant. Therefore, we measured fluid transport and mucosal electrolyte composition in primary cultures of CF airway epithelia without holding transepithelial voltage and ion concentration gradients at zero. In normal epithelia, cAMP agonists plus amiloride stimulated $\mathrm{NaCl}$ and fluid secretion. In $\mathrm{CF}$ epithelia, cAMP agonists failed to stimulate fluid or electrolyte secretion, changes consistent with the loss of CFTR $\mathrm{Cl}^{-}$channels. But in striking contrast to predictions based on Ussing chamber studies, CF epithelia absorbed fluid at a rate no greater than normal epithelia. Moreover, amiloride, which inhibits $\mathrm{Na}^{+}$channels, failed to inhibit fluid absorption by $\mathrm{CF}$ epithelia. These results have important implications for understanding the pathogenesis of CF airway disease and for the design and evaluation of therapy. (J. Clin. Invest. 1994. 93:1307-1311.) Key words: airway surface fluid • airway liquid - $\mathrm{Na}^{+}$absorption $\bullet$ amiloride $\bullet$ open-circuit transport

\section{Introduction}

Cystic fibrosis $(\mathrm{CF})^{1}(1)$ is caused by mutations in the cystic fibrosis transmembrane conductance regulator (CFTR) (2), a

Address correspondence to Dr. Michael J. Welsh, Howard Hughes Medical Institute, Department of Internal Medicine, University of Iowa College of Medicine, Iowa City, IA 52242.

Received for publication 12 October 1993 and in revised form 29 November 1993.

1. Abbreviations used in this paper: CF, cystic fibrosis; CFTR, cystic fibrosis transmembrane conductance regulator; IBMX, 3-isobutyl 1-methylxanthine.

J. Clin. Invest.

(C) The American Society for Clinical Investigation, Inc. $0021-9738 / 94 / 03 / 1307 / 05 \$ 2.00$

Volume 93, March 1994, 1307-1311
$\mathrm{Cl}^{-}$channel regulated by cAMP-dependent phosphorylation and by intracellular nucleotides (for reviews see references 3-5). In normal human airway epithelia, CFTR is located in the apical membrane, where it mediates cAMP-regulated transepithelial $\mathrm{Cl}^{-}$transport (6). In CF airway epithelia, CFTR is missing from the apical membrane or has abnormal function; this defect causes a loss of cAMP-regulated $\mathrm{Cl}^{-}$transport (7). Airway epithelia also possess the cellular mechanisms for $\mathrm{Na}^{+}$ absorption from the mucosal to the submucosal solution $(6,8$, 9). $\mathrm{Na}^{+}$absorption is mediated in part by apical $\mathrm{Na}^{+}$channels that are inhibited by amiloride. Previous studies have shown that CF airway epithelia have a two- to threefold greater rate of active $\mathrm{Na}^{+}$transport than normal epithelia, at least when studied under short circuit, in vitro conditions (8).

The $\mathrm{CF}$-associated increase in $\mathrm{Na}^{+}$transport and the loss of cAMP-regulated $\mathrm{Cl}^{-}$transport are thought to alter the quantity and composition of the respiratory tract fluid, thereby directly contributing to the pathogenesis and pathophysiology of CF airway disease $(1,6,10)$; airway disease is the major cause of morbidity and mortality in CF. However, the relationship between the CF-associated abnormalities in transepithelial $\mathrm{Na}^{+}$ and $\mathrm{Cl}^{-}$transport, measured under voltage-clamped conditions, to in vivo fluid and electrolyte transport is unknown. There have been no studies of fluid transport by CF airway epithelia, either in vivo or in vitro, and there is little information on how the composition of $\mathrm{CF}$ airway fluid may differ from that of normals $(11,12)$.

The goal of this study was to test the hypothesis that fluid transport is abnormal in CF airway epithelia. We attempted to mimic the in vivo situation by using primary cultures of $\mathrm{CF}$ airway epithelia grown on permeable filter supports in the absence of a voltage clamp and with a small mucosal fluid volume. The methods for measuring fluid volume and composition were adapted from those originally described by Grantham et al. and Mangoo-Karim $(13,14)$ and are identical to those we previously reported (15). Primary cultures of human airway epithelia were grown on permeable filter supports, a small amount of fluid was placed on the mucosal surface, and then the fluid was covered by a thin layer of mineral oil to minimize evaporation. $24 \mathrm{~h}$ later, we measured the volume and electrolyte composition of the fluid. We also determined how fluid transport was altered by two agents previously shown to alter electrolyte transport by airway epithelia studied under voltage-clamped conditions. We examined the effect of amiloride, a diuretic that blocks $\mathrm{Na}^{+}$channels (8); amiloride is currently being investigated for inhalation by patients with $\mathrm{CF}$ in an attempt to inhibit $\mathrm{Na}^{+}$absorption $(16,17)$. We also examined the effect of cAMP agonists (forskolin and 3-isobutyl 1-methylxanthine [IBMX]); cAMP agonists are of particular interest because they activate phosphorylation-regulated CFTR $\mathrm{Cl}^{-}$channels in the apical membrane and, in the presence of amiloride, they stimulate $\mathrm{Cl}^{-}$and fluid secretion (15). 
Based on previous in vitro studies done under voltageclamped (short circuit) conditions, we expected that the basal rate of fluid absorption would be increased in CF epithelia, that amiloride would inhibit fluid absorption, and that $\mathrm{CF}$ epithelia would fail to secrete fluid in response to the combination of amiloride and cAMP agonists.

\section{Methods}

Cell culture. Nasal polyps were obtained, after polypectomy, from six patients with CF. Airway epithelial cells were isolated by enzyme digestion as previously described (15). Freshly isolated cells were seeded at a density of $5 \times 10^{5}$ cells $/ \mathrm{cm}^{2}$ onto collagen-coated, semipermeable membranes (24-mm diameter Transwell; Costar, Cambridge, MA) and maintained at $37^{\circ} \mathrm{C}$ in a humidified atmosphere of $5 \% \mathrm{CO}_{2}$ in air. The culture media, a mixture of 50\% DME and 50\% Ham's F12 (DME/F12), was supplemented with $10 \mu \mathrm{g} / \mathrm{ml}$ insulin, $5 \%$ fetal calf serum (Sigma Chemical Co., St. Louis, MO), $10 \mathrm{mM}$ nonessential amino acids (Irvine Scientific, Santa Ana, CA), $100 \mathrm{U} / \mathrm{ml}$ penicillin, and $100 \mu \mathrm{g} / \mathrm{ml}$ streptomycin. To assess the confluency of the monolayers, transepithelial resistance was measured with an ohmmeter (EVOM; World Precision Instruments, Sarasota, FL); all epithelia had transepithelial electrical resistances $\geq 900 \Omega \cdot \mathrm{cm}^{2}$, indicating the confluency and integrity of the epithelial monolayers.

Fluid transport. The methods for measuring fluid volume and composition were adapted from those originally described by Grantham et al. and Mangoo-Karim et al. $(13,14)$ and are precisely identical to those we previously reported (15). At the start of the experiment, the submucosal solution was replaced with $2.5 \mathrm{ml}$ of fresh media (supplemented as described above) and $100 \mu \mathrm{l}$ of serum-free media was placed on the mucosal surface. Assuming a uniform distribution of fluid over the epithelium, the depth of fluid on the mucosal surface at the start of the experiment is calculated to be $220 \mu \mathrm{m}$. It was necessary to begin the experiment with some fluid on the mucosal surface because preliminary studies showed that if we began with no fluid on the mucosal surface, under most conditions we could not recover sufficient fluid for analysis. To minimize evaporative losses, the mucosal solution was covered with $1.5 \mathrm{ml}$ of filter-sterilized mineral oil (previously warmed to $37^{\circ} \mathrm{C}$, humidified, and equilibrated with $5 \% \mathrm{CO}_{2}$ ). Covering the mucosal solution with mineral oil did not alter the transport properties of epithelia (15). After adding $100 \mu \mathrm{l}$ of fluid to the mucosal surface of epithelia, $95.4 \pm 0.9 \mu \mathrm{l}(n=20)$ could be recovered $5 \mathrm{~min}$ later. This value $(95.4 \mu \mathrm{l})$ served as the zero volume, i.e., the volume recovered if there is no net transport. To determine whether evaporation produced volume changes, we performed identical experiments except that glass coverslips replaced the epithelium. The volume recovered $5 \mathrm{~min}$ later was $99.0 \pm 0.5 \mu \mathrm{l}(n=5)$ and the volume recovered $24 \mathrm{~h}$ later was $97.9 \pm 0.4(n=6)$. These results indicate that evaporation made no significant contribution to the observed changes.

Monolayers were exposed to one of the following conditions: $(a)$ control, no inhibitors or secretagogues; $(b)$ cAMP agonists, $10 \mu \mathrm{M}$ forskolin and $100 \mu \mathrm{M}$ IBMX added to the submucosal solution; (c) amiloride $(30 \mu \mathrm{M})$ added to the mucosal solution; or $(d)$ amiloride plus cAMP agonists, final concentrations as indicated above. After 24 h, mucosal and submucosal solutions were collected for analysis. Mucosal solutions were collected in capillary tubes to measure the recovered volume using the length of the aqueous fluid column and the known internal diameter of the capillary tubes (custom glass tubing; Drummond Scientific, Broomall, PA). $\mathrm{Na}^{+}$and $\mathrm{K}^{+}$concentrations were measured with a flame photometer (Instrumentation Laboratory, Boston, $\mathrm{MA}$ ), and $\mathrm{Cl}^{-}$concentration was measured with a chloridometer (Laboratory Glass and Instruments Corp., New York, NY) (15). Neither $\mathrm{Na}^{+}$nor $\mathrm{Cl}^{-}$concentrations were significantly modified by addition of amiloride, forskolin, and IBMX, or by supplementing the media with serum. However, $\mathrm{K}^{+}$concentrations in serum-supplemented media $(4.46 \pm 0.01 \mathrm{mM})$ were significantly greater than in unsupplemented media $(4.04 \pm 0.02 \mathrm{mM} ; n=20)$. Amiloride was a gift from Merck, Sharp and Dohme Research (West Point, PA). All other chemicals were purchased from Sigma Chemical Co.

Data analysis. Values represent mean \pm SEM of data from six different CF patients: two were homozygous for $\triangle \mathrm{F} 508$ and four were heterozygous for $\Delta F 508$ ( $\Delta F 508 /$ unknown mutation ). One to six cell monolayers from a single patient were studied for each condition; when more than one monolayer from a patient was studied, a single average value for that condition was obtained. Values for 12 non-CF nasal polyps are from reference 15 .

Validation of the methods. Although we previously published the use of this technique in normal airway epithelia (15), several additional considerations indicate the validity of the methods.

(a) Variability occurs as a result of differences between epithelia from different subjects, but there was little variability between measurements in epithelia obtained from the same subject. The coefficients of variation for fluid volume measurements made on multiple $(n=3-6)$ monolayers from the same epithelial sample under a specific condition were $3.0 \pm 0.4 \%$ for CF epithelia $(n=7)$ and $6.5 \pm 1.4 \%$ for normal epithelia $(n=10)$.

(b) Osmotic gradients generated by addition of mannitol (values from $42 \mathrm{mOsm}$ directed to the submucosal solution to $28 \mathrm{mOsm}$ directed to the mucosal solution) induced fluid transport in the direction of the gradient at a rate of $0.48 \mu \mathrm{l} \cdot \mathrm{cm}^{-2} / 24 \mathrm{~h}$ per mOsm $\left(R^{2}=0.99, n\right.$ $=20$ ).

(c) Measurement of volume change by indicator dilution using $\left[{ }^{3} \mathrm{H}\right]$ inulin predicted a volume flux $\left(\mathrm{J}_{\mathrm{v}}\right)$ of $-21 \pm 8 \mu \mathrm{l} \cdot \mathrm{cm}^{-2} / 24 \mathrm{~h}$, which was similar to our direct measurement of $-24.7 \pm 0.9 \mu \mathrm{l} \cdot \mathrm{cm}^{-2}$ / $24 \mathrm{~h}$ on the same epithelial monolayers $(n=8)$.

(d) When epithelia were incubated with submucosal ouabain ( 100 $\mu \mathrm{M}$ ) for $24 \mathrm{~h}$ to inhibit the Na-K-ATPase, net volume changes were abolished $(n=6)$.

(e) Time course studies performed under identical conditions using T84 intestinal epithelial cells stimulated with cAMP agonists showed linear increases in mucosal fluid volume. There was no secretion under basal conditions. After addition of cAMP agonists, fluid secretion was $1.01 \mu \mathrm{l} \cdot \mathrm{cm}^{-2} / \mathrm{h}$ over the course of $24 \mathrm{~h}(n=2$ at time points of $2,4,6,9,15$, and $24 \mathrm{~h}, R^{2}=0.97$ ).

$(f)$ Finally, and most importantly, interventions such as addition of amiloride and cAMP agonists produced consistent and reproducible changes in volume and fluid composition in normal and CF epithelia.

\section{Results and Discussion}

Fig. $1 A$ shows that under basal conditions, CF epithelia absorbed fluid. Fluid absorption was accompanied by net $\mathrm{Na}^{+}$ absorption (Fig. $1 B$ ), which reduced the mucosal fluid $\mathrm{Na}^{+}$ concentration (Fig. 1 D). Net $\mathrm{Cl}^{-}$transport was negligible (Fig. $1 C$ ), but because there was net fluid absorption, the mucosal fluid $\mathrm{Cl}^{-}$concentration increased to values greater than those in the submucosal solution (Fig. $1 E$ ). Our previous studies suggest that $\mathrm{Na}^{+}$absorption is accompanied at least in part by $\mathrm{HCO}_{3}^{-}$.

In Fig. 1 we also compare data from CF epithelia with data obtained in normal epithelia studied under identical conditions during the same time period (15). The results show that fluid absorption was no greater in CF than in normal epithelia. This finding was unexpected, because previous studies done under short circuit conditions in Ussing chambers found that the rate of electrogenic amiloride-sensitive $\mathrm{Na}^{+}$absorption is increased in CF airway epithelia $(8,9)$.

Despite the fact that there was no difference between CF and normal epithelia in fluid absorption, as has been previously reported, we found increased $\mathrm{Na}^{+}$absorption measured as the amiloride-sensitive short circuit current $\left(\mathrm{I}_{\mathrm{sc}}\right)$. In normal airway epithelia, $I_{s c}$ was $5.0 \pm 0.4 \mu \mathrm{A} / \mathrm{cm}^{2}$ under basal condi- 

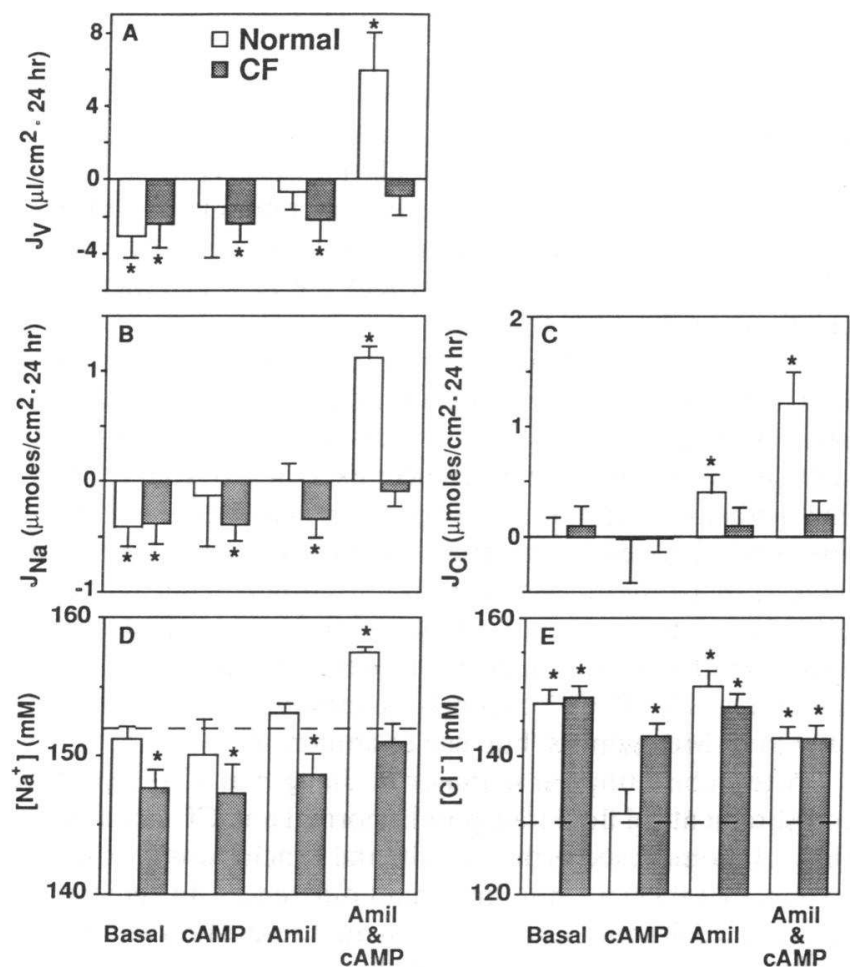

Figure 1. Effect of amiloride and cAMP agonists on the net transport of $(A)$ fluid, $(B) \mathrm{Na}^{+}$, and $(C) \mathrm{Cl}^{-}$and on the mucosal concentration of $(D) \mathrm{Na}^{+}$and $(E) \mathrm{Cl}^{-}$in normal (open bars) and CF (stippled bars) airway epithelia. $(A-C) \mathrm{J}$ indicates flux, zero indicates no net transport, positive values indicate net secretion into the mucosal solution, and negative values indicate net absorption. ( $D$ and $E$ ) Dashed lines indicate the $\mathrm{Na}^{+}(151.8 \pm 0.5 \mathrm{mM}$, mean $\pm \mathrm{SEM})$ and $\mathrm{Cl}^{-}$ ( $130.6 \pm 0.4 \mathrm{mM}$ ) concentrations of the submucosal solution, which were the same for all conditions, Amil indicates the presence of 30 $\mu \mathrm{M}$ amiloride in the mucosal solution, and cAMP indicates the presence of $10 \mu \mathrm{M}$ forskolin and $100 \mu \mathrm{M}$ IBMX in the submucosal solution. Asterisks indicate values significantly $(P<0.05$, unpaired $t$ test) different from zero in $A-C$ and different from submucosal values in $D$ and $E$.

tions ( $n=42$ epithelia from five subjects) and decreased by $3.2 \pm 0.3 \mu \mathrm{A} / \mathrm{cm}^{2}$ after addition of amiloride $(10 \mu \mathrm{M}$, mucosal solution ), whereas in CF epithelia, $\mathrm{I}_{\mathrm{sc}}$ was $10.2 \pm 0.8 \mu \mathrm{A} / \mathrm{cm}^{2}(n$ $=53$ epithelia from seven subjects) and decreased by $8.2 \pm 0.7$ $\mu \mathrm{A} / \mathrm{cm}^{2}$ after adding amiloride. Thus, the amiloride-sensitive $\mathrm{I}_{\mathrm{sc}}$ was two- to threefold greater in CF epithelia $(P<0.001)$.

Although results from Ussing chamber studies did not predict changes in fluid transport, Ussing chamber studies differ from the conditions we used to measure fluid transport (and from in vivo conditions) in two important ways. First, transepithelial voltage is clamped (held constant at zero); clamping transepithelial voltage to zero can alter ion transport by abolishing net electrolyte movement through the paracellular pathway, by altering the voltage across apical and basolateral membranes, and by changing intracellular ion concentrations. Second, mucosal fluid composition is clamped (held constant by virtue of its large volume and the relatively short duration of study); in vivo the mucosal fluid volume is small, so that its composition can be altered by the epithelium and the resulting transepithelial ion concentration gradients may affect net fluid and electrolyte transport. The potential difficulties inherent in such predictions have been previously noted (6). Moreover, previous Ussing chamber studies that measured $\mathrm{Na}^{+}$transport with radioisotopes when transepithelial voltage was not clamped to zero found that there was no significant difference in the rate of net $\mathrm{Na}^{+}$transport between primary cultures of normal $\left(1.2 \pm 0.4 \mu \mathrm{Eq} \cdot \mathrm{cm}^{-2} / \mathrm{h}\right)(18)$ and $\mathrm{CF}(1.8 \pm 0.7$ $\left.\mu \mathrm{Eq} \cdot \mathrm{cm}^{-2} / \mathrm{h}\right)(19)$ airway epithelia. Results with native airway epithelia have been variable $(20,21)$.

Fig. 1 also shows that cAMP agonists had no effect on net fluid, $\mathrm{Na}^{+}$, or $\mathrm{Cl}^{-}$transport in $\mathrm{CF}$ epithelia. This observation was also unexpected, because earlier studies in $\mathrm{CF}$ epithelia showed that cAMP agonists stimulate $\mathrm{Na}^{+}$absorption under short circuit current conditions (8).

Previous studies have shown that addition of amiloride to the mucosal surface of airway epithelia inhibits $\mathrm{Na}^{+}$channels and electrogenic $\mathrm{Na}^{+}$absorption $(6,8,9)$, and we previously reported that amiloride inhibited net fluid absorption (15). However, in contrast to normal airway epithelia, in CF epithelia amiloride failed to inhibit fluid absorption and did not alter net $\mathrm{Na}^{+}$or $\mathrm{Cl}^{-}$transport (Fig. 1, $A-C$ ). These results suggest that, as previously reported, there are amiloride-insensitive absorptive mechanisms in airway epithelia $(22,23)$.

The failure of amiloride to inhibit fluid absorption (Fig. 1) cannot be attributed to leak of amiloride from the mucosal solution or to inactivity of the compound, because we obtained similar results in normal and CF epithelia when benzamil ( 3 $\mu \mathrm{M})$, a more selective and potent inhibitor of apical $\mathrm{Na}^{+}$channels (24), was added to both mucosal and submucosal solutions (data not shown). Moreover, mucosal amiloride significantly decreased the mucosal $\mathrm{K}^{+}$concentration in CF epithelia $\left(\mathrm{K}^{+}\right.$concentration was $4.64 \pm 0.22 \mathrm{mM}$ under control conditions and 3.86 $\pm 0.16 \mathrm{mM}$ in amiloride-treated epithelia; $n=6$, $P=0.007$ ), indicating that amiloride did have an effect on the epithelium.

We considered the possibility that amiloride-insensitive mechanisms contribute to fluid absorption. Previous studies have demonstrated the presence of $\mathrm{Na}$ glucose absorption by airway epithelia (22). Therefore, we examined the effect of glucose and amino acids in the mucosal solution on net fluid transport by normal airway epithelia (Fig. 2). To eliminate the effect of amiloride-sensitive transport, amiloride ( $30 \mu \mathrm{M})$ was

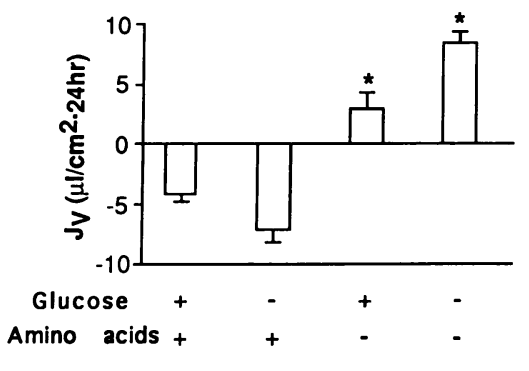

Figure 2. Effect of glucose and amino acids on amiloride-insensitive fluid transport by normal epithelia. The plus sign at the bottom of the figure indicates the presence of glucose $(17.5 \mathrm{mM})$ or amino acids in the mucosal solution; amino acids were added as $2.9 \mathrm{ml}$ nonessential amino acids and $2.7 \mathrm{ml}$ essential amino acids (both from Sigma Chemical Co.) for each $100 \mathrm{ml}$ of mucosal solution. The mucosal solution contained $(\mathrm{mM}): \mathrm{NaCl}$, $119.8 ; \mathrm{KCl}, 4.18 ; \mathrm{NaHCO}_{3}, 24.2 ; \mathrm{CaCl}_{2}, 1.8$; and $\mathrm{MgSO}_{4}, 0.8$. Transepithelial osmotic gradients were eliminated by substituting mannitol for glucose or amino acids. Amiloride was included in the mucosal solution to reduce amiloride-sensitive transport. Other details are as in Fig. 1. Values are mean \pm SEM, $n=4{ }^{*}$ Values that differ significantly from transport when amino acids were present in the mucosal solution. 
added to the mucosal solution. When glucose and amino acids were present in the mucosal solution, the epithelia absorbed fluid. When amino acids were replaced by mannitol, fluid absorption was abolished, and secretion was observed. Removal of glucose alone had no significant effect.

These results suggest that amiloride-insensitive mechanisms may account for some of the fluid absorption by airway epithelia. This can explain, in part, the fluid absorption we observed in CF epithelia studied in the presence of amiloride. Yet, why did amiloride inhibit fluid absorption by normal epithelia?

By inhibiting apical membrane $\mathrm{Na}^{+}$channels, amiloride hyperpolarizes apical membrane voltage (9). Hyperpolarization increases the driving force for $\mathrm{Cl}^{-}$exit through apical membrane CFTR $\mathrm{Cl}^{-}$channels (25), some of which are open under basal conditions (26). As a result, we measured net $\mathrm{Cl}^{-}$ secretion (Fig. $1 C$ ). The resulting fluid secretion counterbalances amiloride-insensitive fluid absorption. Thus, net fluid absorption was abolished in normal epithelia (Fig. $1 A$ ). The lack of effect of amiloride on net fluid transport in CF epithelia can be explained by a lack of functional CFTR $\mathrm{Cl}^{-}$channels and hence a lack of $\mathrm{Cl}^{-}$and fluid secretion to counterbalance amiloride-insensitive fluid absorption.

If this proposed mechanism of amiloride's effect on fluid transport is correct, we reasoned that if we reduced apical $\mathrm{Cl}^{-}$ conductance of normal epithelia, then amiloride should be less effective at inhibiting fluid absorption. Thus, we would have a situation similar to that observed in CF epithelia. To reduce apical $\mathrm{Cl}^{-}$conductance, we added indomethacin $(3 \mu \mathrm{M})$ to inhibit endogenous prostaglandin production and reduce cellular levels of cAMP $(27,28)$. For this experiment, glucose and amino acids in the mucosal solution were replaced with mannitol to reduce amiloride-insensitive absorption. Fig. 3 shows that under these conditions, the basal rate of fluid transport was near zero and indomethacin had no effect.

When we added amiloride to the mucosal solution of control monolayers, we stimulated fluid secretion. This observation is consistent with our proposal that amiloride stimulates $\mathrm{Cl}^{-}$secretion in normal epithelia by increasing the electrical driving force across the apical membrane. The fact that amiloride inhibited fluid absorption in Fig. 1 and stimulated secretion in Fig. 3 is explained by the lack of glucose and amino acids in the experiment shown in Fig. 3.

However, the key observation in Fig. 3 is that in the presence of indomethacin, amiloride failed to alter the rate of fluid transport. This is the same result that was obtained with CF epithelia. These observations suggest that the predominant ef-

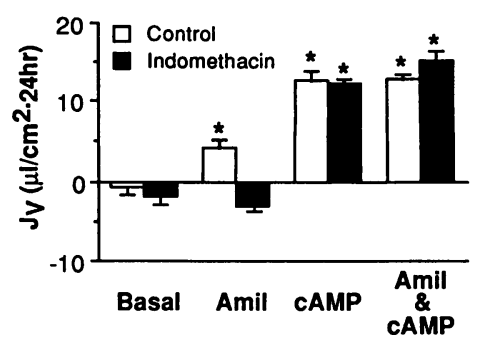

Figure 3. Effect of indomethacin $(3 \mu \mathrm{M})$ on net fluid transport by normal epithelia. To eliminate amiloride-insensitive absorption, glucose and amino acids were not included in the mucosal solution (Ringer's solution as indicated in Fig. 2). Other details are as in Fig. 1. Values are mean \pm SEM, $n=5$. *Values that differ significantly from zero. fect of amiloride on fluid transport results from stimulation of secretion.

When we added the combination of amiloride plus cAMP agonists, we stimulated $\mathrm{Na}^{+}, \mathrm{Cl}^{-}$, and fluid secretion in normal epithelia (15). In contrast, amiloride plus cAMP agonists failed to stimulate fluid and electrolyte secretion in CF epithelia (Fig. $1, A-C$ ). These results are consistent with the role of CFTR $\mathrm{Cl}^{-}$channels in secretion and the lack of functional CFTR channels in CF epithelia.

Our data indicate that fluid transport by $\mathrm{CF}$ airway epithelia is defective, but the results are different from predictions based on measurements of amiloride-sensitive $\mathrm{Na}^{+}$transport in Ussing chambers. The differences likely result from the fact that neither transepithelial voltage nor mucosal fluid composition were clamped in our study. We interpret our results to indicate that amiloride-sensitive $\mathrm{Na}^{+}$transport is not a reliable predictor of the direction or rate of fluid movement across airway epithelia. The data do, however, suggest that apical membrane CFTR $\mathrm{Cl}^{-}$channels determine the response not only to cAMP agonists, but also to amiloride.

After submitting our manuscript, Jiang et al. (29) reported measurements of fluid transport in normal and CF airway epithelia. In some respects their results and conclusions are similar to ours, but there are also important differences. In agreement with our results, they found: $(a)$ that fluid absorption was inhibited by amiloride in normal epithelia; $(b)$ that cAMP agonists stimulated fluid secretion in normal epithelia; $(c)$ that cAMP agonists failed to stimulate secretion in CF epithelia; and (d) that cAMP agonists failed to increase fluid absorption in CF epithelia. However, in contrast to our results, they found that the rate of fluid transport was greater in CF than in normal epithelia and that amiloride inhibited fluid absorption in CF epithelia. We believe that the difference in results may be due to differences in the experimental methods. Both studies were carried out under open circuit conditions, but in the study of Jiang et al. (29), the mucosal solution contained a large volume of fluid and the duration of experimental interventions was 20-30 min. Thus, a major difference from our study is that mucosal fluid volume and composition were held constant in their study. As a result, active and passive electrolyte and fluid transport were not able to alter the composition of the mucosal solution, which in turn could modulate net transport. The methods of cell culture were also slightly different. But this difference is not likely responsible for the differences in results because when we used culture methods similar to those reported by Jiang et al. (29), we obtained results qualitatively identical to those we report here. In the end, an understanding of what factors account for the differences between our study and that of Jiang et al. may provide important new insights into airway epithelial function.

These results begin to provide insight into how the genetic defect in CFTR produces defective respiratory tract fluid. They also have important implications for the design and evaluation of therapy by suggesting that correction of the fluid transport defect in CF epithelia may require restoration of apical membrane $\mathrm{Cl}^{-}$conductance.

\section{Acknowledgments}

We thank Lisa DeBerg, Elizabeth Burton, Corinne Conner, and Theresa Mayhew for technical assistance. We especially appreciate discussions with Dr. John B. Stokes III, as well as the use of his flame photometer. 
This work was supported in part by the March of Dimes Birth Defects Foundation (Research Award 1-FY91-0176), the National Heart, Lung and Blood Institute (HL-42385), the Cystic Fibrosis Foundation, and the Howard Hughes Medical Institute. M. J. Welsh is an Investigator of the Howard Hughes Medical Institute.

\section{References}

1. Boat, T. F., M. J. Welsh, and A. L. Beaudet. 1989, Cystic fibrosis. In The Metabolic Basis of Inherited Disease. C. R. Scriver, A. L. Beaudet, W. S. Sly, and D. Valle. editors. McGraw-Hill Inc., New York. 2649-2680.

2. Riordan, J. R., J. M. Rommens, B.-S. Kerem, N. Alon, R. Rozmahel, Z. Grzelczak, J. Zielenski, S. Lok, N. Plavsic, J.-L. Chou, et al. 1989. Identification of the cystic fibrosis gene: cloning and characterization of complementary DNA. Science (Wash. DC). 245:1066-1073.

3. Welsh, M. J., M. P. Anderson, D. P. Rich, H. A. Berger, G. M. Denning L. S. Ostedgaard, D. N. Sheppard, S. H. Cheng, R. J. Gregory, and A. E. Smith. 1992. Cystic fibrosis transmembrane conductance regulator: a chloride channel with novel regulation. Neuron. 8:821-829.

4. Collins, F. S. 1992. Cystic fibrosis: molecular biology and therapeutic implications. Science (Wash. DC). 256:774-779.

5. Riordan, J. R. 1993. The cystic fibrosis transmembrane conductance regulator. Annu. Rev. Physiol. 55:609-630.

6. Quinton, P. M. 1990. Cystic fibrosis: a disease in electrolyte transport. FASEB (Fed. Am. Soc. Exp. Biol.) J. 4:2709-2717.

7. Welsh, M. J., and A. E. Smith. 1993. Molecular mechanisms of CFTR chloride channel dysfunction in cystic fibrosis. Cell. 73:1251-1254.

8. Boucher, R. C., M. J. Stutts, M. R. Knowles, L. Cantley, and J. T. Gatzy. 1986. $\mathrm{Na}^{+}$transport in cystic fibrosis respiratory epithelia. Abnormal basal rate and response to adenylate cyclase activation. J. Clin. Invest. 78:1245-1252.

9. Boucher, R. C., C. U. Cotton, J. T. Gatzy, M. R. Knowles, and J. R. Yankaskas. 1988. Evidence for reduced $\mathrm{Cl}^{-}$and increased $\mathrm{Na}^{+}$permeability in cystic fibrosis human primary cell cultures. J. Physiol. (Lond.). 405:77-103.

10. Boucher, R. C., M. R. Knowles, M. J. Stutts, and J. T. Gatzy. 1983. Epithelial dysfunction in cystic fibrosis lung disease. Lung. 161:1-17.

11. Cherniak, W. S., and G. J. Barbero. 1959. Composition of tracheobronchial secretions in cystic fibrosis of the pancreas and bronchiectasis. Pediatrics. 24:739-745.

12. Matthews, L. W., S. Spector, J. Lemm, and J. L. Potter. 1968. Studies on pulmonary secretions. Am. Rev. Respir. Dis. 88:199-204.

13. Grantham, J. J., M. Uchic, E. J. J. Cragoe, J. Kornhaus, J. A. Grantham, V. Donoso, R. Mangoo-Karim, A. Evan, and J. McAteer. 1989. Chemical modification of cell proliferation and fluid secretion in renal cysts. Kidney Int. 35:13791389.
14. Mangoo-Karim, R., M. E. Uchic, M. Grant, W. A. Shumate, J. P. Calvet, C. H. Park, and J. J. Grantham. 1989. Renal epithelial fluid secretion and cyst growth: the role of cyclic AMP. FASEB (Fed. Am. Soc. Exp. Biol.) J. 3:26292632.

15. Smith, J. J., and M. J. Welsh. 1993. Fluid and electrolyte transport by cultured human airway epithelia. J. Clin. Invest. 91:1590-1597.

16. Knowles, M. R., N. L. Church, W. E. Waltner, J. R. Yankaskas, P. Gilligan, M. King, L. J. Edwards, R. W. Helms, and R. C. Boucher. 1990. A pilot study of aerosolized amiloride for the treatment of lung disease in cystic fibrosis. N. Engl. J. Med. 322:1189-1194.

17. App, E. M., M. King, R. Helfesrieder, D. Kohler, and H. Matthys. 1990. Acute and long-term amiloride inhalation in cystic fibrosis lung disease. A rational approach to cystic fibrosis therapy. Am. Rev. Respir. Dis. 141:605-612.

18. Willumsen, N. J., and R. C. Boucher. 1991. Sodium transport and intracellular sodium activity in cultured human nasal epithelium. Am. J. Physiol. 261:C319-C331.

19. Willumsen, N. J., and R. C. Boucher. 1991. Transcellular sodium transport in cultured cystic fibrosis human nasal epithelium. Am. J. Physiol 261:C332-C341.

20. Boucher, R. C., M. J. Stutts, M. R. Knowles, and J. T. Gatzy. 1986. Raised rate of $\mathrm{NaCl}$ absorption across excised cystic fibrosis nasal epithelia under opencircuit conditions. Clin. Res. 34:574a. (Abstr.)

21. Alton, E. W. F. W., D. F. Rogers, R. Logan-Sinclair, M. Yacoub, P. J. Barnes, and D. M. Geddes. 1992. Bioelectric properties of cystic fibrosis airways obtained at heart-lung transplantation. Thorax. 47:1010-1014.

22. Joris, L., and P. M. Quinton. 1989. Evidence for electrogenic Na-glucose cotransport in tracheal epithelium. Pfluegers Arch. Eur. J. Physiol. 415:118-120.

23. Steel, D. M., A. Graham, E. W. F. W. Alton, and D. M. Geddes. 1991. Characterization of the macroscopic short-circuit current across sheep and human airway epithelium with isolation of the $\mathrm{Cl}^{-}$components. Pediatr. Pulmonol. Suppl. 6:267. (Abstr.)

24. Kleyman, T. R., and E. J. Cragoe, Jr. 1988. Amiloride and its analogs as tools in the study of ion transport. J. Membr. Biol. 105:1-21.

25. Welsh, M. J. 1987. Electrolyte transport by airway epithelia. Physiol. Rev. 67:1143-1184.

26. Anderson, M. P., and M. J. Welsh. 1991. Calcium and cAMP activate different chloride channels in the apical membrane of normal and cystic fibrosis epithelia. Proc. Natl. Acad. Sci. USA. 88:6003-6007.

27. Smith, P. L., M. J. Welsh, J. W. Stoff, and R. A. Frizzell. 1982. Chloride secretion by canine tracheal epithelium. I. Role of intracellular cAMP levels. $J$. Membr. Biol. 70:217-226.

28. Xu, G. L., K. Sivarajah, R. Wu, P. Nettesheim, and T. Eling. 1986. Biosynthesis of prostaglandins by isolated and cultured airway epithelial cells. Exp. Lung Res. 10:101-114.

29. Jiang, C., W. E. Finkbeiner, J. H. Widdicombe, P. B. McCray, Jr., and S. S. Miller. 1993. Altered fluid transport across airway epithelium in cystic fibrosis. Science (Wash. DC). 262:424-427. 